\title{
Revisão das aranhas do gênero Lupettiana Brescovit (Araneae, Anyphaenidae, Anyphaeninae)
}

\author{
Antonio D. Brescovit ${ }^{1}$
}

\begin{abstract}
Revision of the spider genus Lupettiana Brescovit (Araneae, Anyphaenidae, Anyphaeninae). The genus Luppetiana Brescovit, 1996 composed actually by nine species, from which five are herein described as new is revised: $L$. manauara from Brazil; L. levii from Dominican Republic; L. eberhardi from Costa Rica; $L$. piedra from Cuba; and $L$. bimini from Bahamas Islands. The species $L$. perpusilla (Banks, 1909) is synonymyzed with L. parvula (Banks, 1903). Lectotype and paralectotype of $L$. parvula are designated. The known geographical distribution of the genus ranges from United States of America to north of Brazil.

KEY WORDS. Araneae, Anyphaenidae, Anyphaeninae, Lupettiana, Neotropical region, systematics
\end{abstract}

O gênero Lupettiana Brescovit, 1996, aqui revisado, tem como base à espécie-tipo L. linguanea Brescovit, 1996, da Jamaica. Além desta foram incluidas no gênero outras quatro espécies: L. mordax (O.P.-Cambridge, 1896), transferida do gênero Teudis O.P.-Cambridge, 1896 e as outras três oriundas do gênero Temnida Simon, 1896: L. parvula (Banks, 1903), L. perpusilla (Banks, 1909) e L. spinosa (Bryant, 1948).

As espécies de Lupettiana em geral apresentam pequeno porte, não ultrapassando os 5,5 mm de comprimento, habitam arbustos e são diagnosticadas em relação aos demais gêneros, principalmente, pelos caracteres da genitália dos machos. Estes apresentam o condutor de Anyphaeninae (CA), em geral estreito e achatado, o qual pode ser curto ou muito longo (Figs 6, 13; BRESCOVIT 1996, figs 153, 157) e parece ser exclusivo de Lupettiana e dos gêneros Xiruana Brescovit, 1996 e Pippuhana Brescovit, 1996. Espécies da subfamília Amaurobioidinae, (Anyphaenidae) apresentam o "condutor secundário de Amaurobioidinae", uma estrutura que poderia ser homóloga do CA e está localizada na região distal do tégulo do palpo dos machos, próxima do êmbolo (RAMíREZ 1995: fig. 27). A homologia desta estrutura foi discutida por BRESCOVIT (1996: 119) e as evidências apontaram para três origens independentes, uma para Lupettiana, outra para o que parece ser o grupo irmão Xiruana + Pippuhana, pertencentes ao grupo Aysha Keyserling, 1891, exibindo o processo embólico (BRESCOVIT 1996: figs 276, 299) e uma outra para os Amaurobioidinae.

Neste trabalho são incluídas nove espécies, quatro das cinco acima citadas, uma vez que $L$. perpusilla (Banks) é aqui considerada sinônimo de $L$. parvula (Banks) e as outras cinco espécies são descritas como novas.

$\mathrm{O}$ material examinado pertence às seguintes coleções (curadores entre parênteses): AMNH - American Museum of Natural History, Nova Iorque (N.I.

1) Laboratório de Artrópodes, Instituto Butantan. Avenida Vital Brasil 1500, 05503-900 São Paulo, São Paulo, Brasil. 
Platnick); BPBM - Bishop Museum, Honolulu (S.F. Swift); CAS - Californian Academy of Sciences, San Francisco (C. Griswold); DU - Coleção particular Darrel Ubick; IBSP - Instituto Butantan, São Paulo (A.D. Brescovit); INPA - Instituto Nacional de Pesquisas da Amazônia, Manaus (C. Magalhães); MACN - Museo Argentino de Ciências Naturales "Bernardino Rivadavia", Buenos Aires (C. Scioscia); MCN - Museu de Ciências Naturais, Fundação Zoobotânica do Rio Grande do Sul, Porto Alegre (E.H. Buckup); MELN - Museu Entomologico, Serviço Entomologico Autonomo Leon, Nicarágua (J.-M. Maes); MCZ - Museum of Comparative Zoology, Cambridge, Mass. (H.W. Levi); MNHN - Museum National de Histoire Naturelle, Paris (C. Rollard); SMNK - Staatliches Museum für Naturkunde, Karlsruhe (H. Höfer).

As descrições e as abreviaturas utilizadas seguem BRESCOVIT (1996). Para o estudo das estruturas internas do epígino utilizou-se a técnica proposta por LEVI (1965). As fotografias foram elaboradas em microscópio de varredura CAMBRIDGE Stereoscan, tipo 73654, do "Laboratorium für Elektronenmikroskopie" da Universidade de Karlsruhe (UK), Karlsruhe, Alemanha. Todas as medidas estão em milímetros $(\mathrm{mm})$.

\section{Lupettiana Brescovit, 1996}

Espécie-tipo. Lupettiana linguanea Brescovit, 1996: 67.

Diagnose. Lupettiana distingue-se dos demais gêneros por apresentar: olhos subiguais em tamanho (Fig. 11); palpo do macho com apófise tibial retrolateral curvada no ápice, formando uma concavidade inferior acentuada (Figs 6-7, 12, indicada por seta); subtégulo basal e distinto, fácilmente visível no palpo não expandido (Figs 2, 12); condutor de Anyphaeninae, entre a projeção tegular ventral distal e a apófise média ou entre esta e o êmbolo (Figs 6, 13); epígino da fêmea com bordas laterais sinuosas ou semicirculares, com área mediana, entre placas pouco esclerotinizada (Figs 8, 14).

Descrição. A descrição do gênero foi apresentada em BRESCOVIT (1996). Aqui é complementada com estruturas não relatadas ou ilustradas anteriormente: carapaça sub-triangular e com sulco torácico raso (Fig. 11). Quelíceras com quase metade do comprimento da carapaça nos machos (Fig. 11) e com dentes grandes e proporcionais em tamanho na retromargem (Fig. 10). Fiandeiras da fêmea: anterior com 7-9 fúsulas das glândulas piriformes e uma fúsula da glândula ampular (fga, Fig. 15); média com 4-5 fúsulas das glândulas piriformes e uma fúsula da glândula ampular secundária (fgs, Fig. 16); posterior com seis fúsulas das glândulas aciniformes (Fig. 17).

Elenco. Nove espécies americanas.

\section{Lupettiana linguanea Brescovit, 1996}

Figs 1-5

Lupettiana linguanea Brescovit, 1996: 67, figs 152-156 (holótipo macho, parátipos dois machos e três fêmeas, MCZ e MCN 24306, Monroe Road, Linguanea, Saint Andrew, Jamaica, 19.X.1957, A.M. Chickering leg., examinados). 
Diagnose. O macho de Lupettiana linguanea difere do de L. mordax pelo palpo apresentar apófise média longa e condutor falciforme (Fig. 2). A fêmea difere pelas bordas laterais do epígino muito estreitas e espermatecas esféricas (Figs 4-5).

Descrição. Macho e fêmea descritos em BRESCOVIT (1996). Palpo do macho: figuras 1-3. Epígino da fêmea: figuras 4-5.

Distribuição geográfica. Jamaica, Guadalupe e Dominica.

Material examinado. Aquele apresentado em BRESCOVIT (1996).

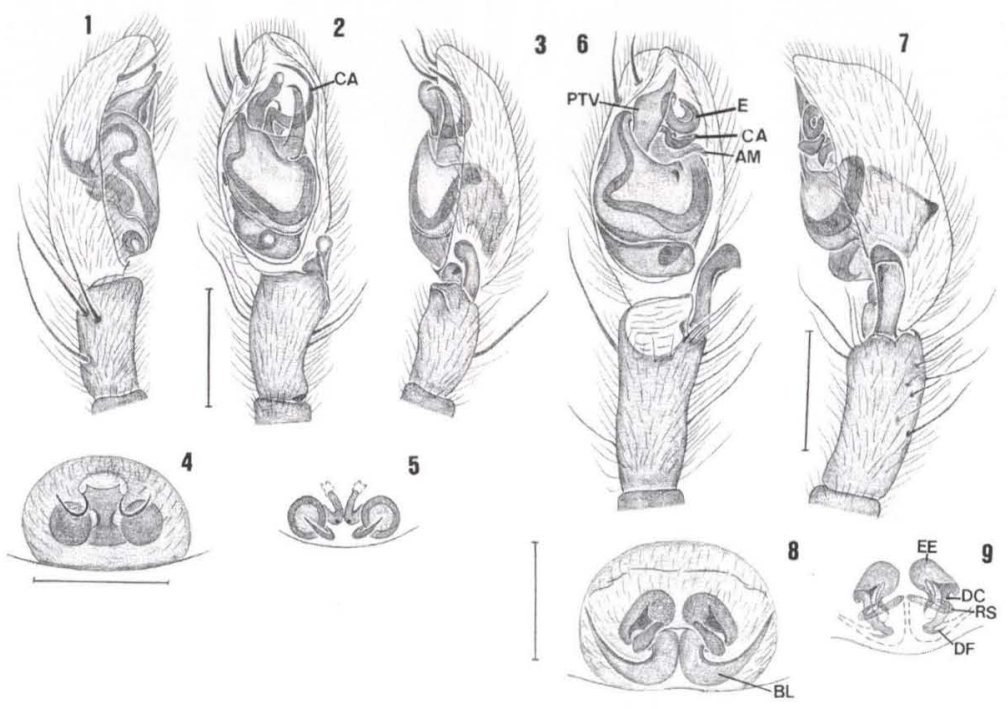

Figs 1-9. (1-5) Lupettiana linguanea, macho, palpo: (1) prolateral, (2) ventral, (3) retrolateral; fêmea, epígino: (4) ventral, (5) dorsal. (6-9) L. mordax (O. P.-Cambridge), macho, palpo: (6) ventral, (7) retrolateral; fêmea, epígino: (8) ventral, (9) dorsal. Escalas: 0,25 mm. (AM) Apófise média, (BL) bordas laterais, (CA) condutor de Anyphaeninae, (DC) ductos de copulação, (DF) ductos de fertilização, (E) êmbolo, (EE) espermatecas, (PTV) projeção tegular ventral, (RS) receptáculo seminal.

\section{Lupettiana mordax (O.P.-Cambridge, 1896)}

Figs 6-17

Delozeugma mordax O.P.-Cambridge, 1896: 182, fig. 11 (holótipo macho, The Natural History Museum, London, de Omiltemi, Guerrero, México, não examinado).

Teudis mordax; O.P.-Cambridge, 1896: 198. - Roewer, 1954: 519. - Bonnet, 1959: 4368. - Platnick, 1974: 263 (comb.n.).

Lupettiana mordax: Brescovit, 1996: 68, figs 157-162.

Sinonímia. A lista sinonímica completa de $L$. mordax pode ser encontrada em BRESCOVIT (1996: 68-69).

Diagnose. O macho de Lupettiana mordax difere do de L. linguanea pela apófise média do palpo muito reduzida e projeção tegular ventral sub-triangular, de ápice cônico (Figs 6,13). A fêmea difere de L. linguanea por apresentar bordas laterais amplas e alargadas e espermatecas ovais (Figs 8-9, 14). 

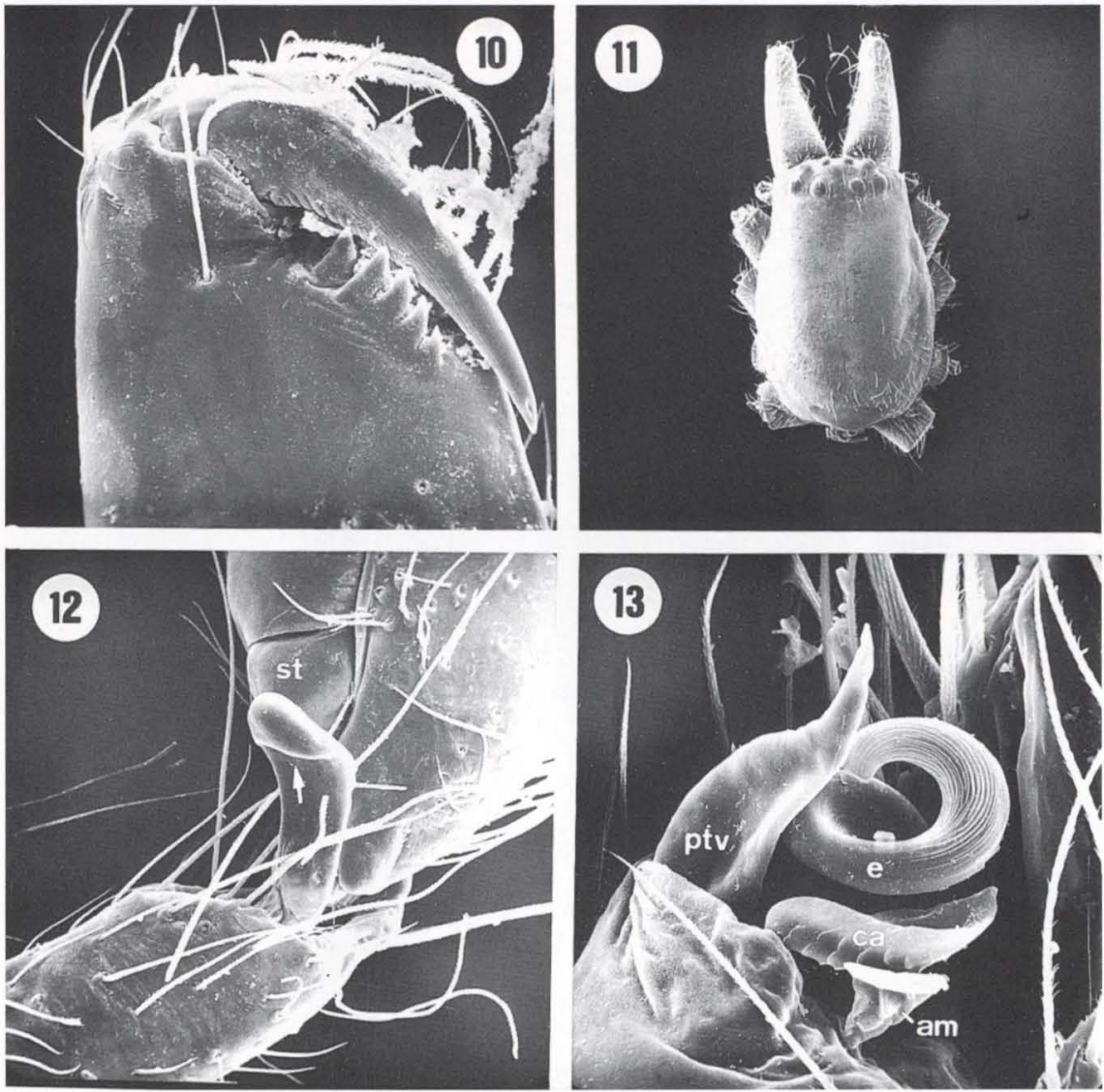

Figs 10-13. Lupettiana mordax, macho. (10) Quelicera, ventral; (11) carapaça, dorsal; (12) palpo macho, retrolateral, seta indicando concavidade inferior do ápice da apófise tibial retrolateral; (13) palpo macho, área distal, ventral. (am) Apófise média, (ca) condutor de Anyphaeninae, (e) êmbolo, (ptv) projeção tegular ventral, (st) subtegulum.

Descrição. Macho e fềmea descritos em BRESCOVIT (1996).

Distribuição geográfica. Estados Unidos, Costa Rica, Panamá, Venezuela, norte do Brasil e Peru.

Novos registros. HonduRAS, Copán: Copán, 1 macho, 5.III.1939 (AMNH). NicaráguA: Rio San Juan, El Castillo, 1 fêmea, VII.1989, F. Reinboldt leg. (MELN). Costa RicA, Cartago: Turrialba, 1 macho, 23.V-13.VIII.1965, A.M. Chickering leg. (MCZ); El Higuito, 1 macho, 20 fêmeas, N. Banks leg. (MCZ, MCN); Limon, 5,5 km E Guapiles (200m alt., Tropical Wet Forest), 1 macho, 09.V.1987, D. Ubick leg. (DU); Puntarenas, 3 km NE Golfito (Tropical Wet Forest), 1 fêmea, 22-23.V.1987, D. Ubick leg. (DU). VENEZUELA: San Esteban, 4 machos, 11 fêmeas (MNHN 11063). COLÔMBIA, Putamayo: Saint Louis, El Pepino (próximo de Mocoa, 1140m alt.), 1 fêmea, 1973, V. Leist leg. (SMNK). BRASIL, Amazonas: Manaus, Lago Janauari (0320'S, 60¹7'W), 1 fêmea, 01.XII.1987, J. 
Adis leg. (SMNK); Pará: Belém, 1 fêmea, 20-30.VIII.1970, M.E. Galiano leg. (MACN); 1 fềmea, 8.II.1959, A.M. Nadler leg. (AMNH); (Instituto Agronômico), 1 macho, 3 fềmea, 11.II.1959, A.M. Nadler leg. (AMNH). PERU, Piura: Amotape, Chira (R. Valley), 3 machos, 8 fêmeas, 31.X.1938 (MCZ); (Rio Chira, próximo de Mallares), 2 machos, 3 fềmeas, 4.I.1932 (CAS); Mallares, 5 machos, 12 fềmeas, 13.VII-7.XII.1941 (CAS, MCN 24310); Sullana (6 km oeste), 6 machos, 4 fêmeas, 5.X.1941 (CAS); Higuerón (Las Lomas); 1 macho, 2 fêmeas, 29.VII.1941 (CAS), todos coletados por D.L. \& H.E. Frizzell; Próximo de Miramar, 4 fêmeas, 09.XI.1941, HSM \& HEF leg. (CAS; IBSP);

\section{Lupettiana parvula (Banks, 1903)}

Figs 18-22

Wulfila parvula Banks, 1903: 340, 342, fig. 4 (sintipos macho e fềmea, MCZ, Port-au-Prince, Haiti, 1899, R.J. Crew leg., examinados). Designa-se lectótipo macho e paralectótipo fêmea.

Anyphaena perpusilla Banks, 1909: 169, fig. 9 (Holótipo fềmea e parátipo fềmea designados por Bryant, 1940: 437), MCZ, Santiago de Las Vegas, Cuba, Baker leg., examinados). Syn.n..

Temnida perpusilla; Bryant, 1940: 436-437, fig. 215.

Temnida parvula; Bryant, 1948: 430-432, figs 112, 113, 119.

Lupettiana parvula; Brescovit, 1996: 67.

Lupettiana perpusilla; Brescovit, 1996: 67.

Diagnose. O macho de Lupettiana parvula difere dos das demais espécies pelo largo e longo condutor de Anyphaeninae, envolvendo o êmbolo (Fig. 18) e grande número de espinhos curtos e grossos no dorso da tíbia do palpo (Fig. 20). O epígino da fêmea que em nada difere de T. perpusilla, parece-se com o de L. spinosa pelas bordas laterais helicoidais, mas difere desta pela menor helicóide, cuja borda lateral é estreita em todo seu comprimento (Fig. 21).

Descrição. Macho (Holótipo de perspusilla). Carapaça e quelíceras marromavermelhadas. Lâminas maxilares, lábio e esterno de colorido laranja. Abdômen amarelo-acinzentado. Pernas alaranjadas, mais escuras junto às articulações.

Comprimento total 3,50. Carapaça: comprimento 1,70, largura 1,30. Clípeo: altura 0,04 . Olhos: fila anterior 0,50 e posterior 0,65 . QOM: comprimento 0,20 , largura anterior 0,20, largura posterior 0,31. Diâmetros: OMA 0,06, OLA 0,08, OMP 0,08, OLP 0,08. Interdistâncias: OMA-OMA 0,06, OMA-OLA 0,05, OMPOMP 0,12, OMP-OLP 0,06, OLA-OLP 0,03. Quelíceras: 1,07 de comprimento, com cinco dentes na promargem e cinco dentículos na retromargem.

Abdômen. Comprimento 1,80, largura 0,80. Espiráculo traqueal distando 0,50 do sulco epigástrico e 0,55 da base das fiandeiras. Pernas I: fêmur $1,40 /$ patela $0,70 /$ tíbia $1,50 /$ metatarso $1,20 /$ tarso $0,55 /$ total $5,35 /$ II: $1,30 / 0,60 / 1,25 / 1,00 /$ 0,50/4,65/ III: 1,00/0,50/0,70/0,90/0,35/3,45/ IV: 1,50/0,60/ 1,30/1,70/ ausente/ 5,10. Espinulação: pernas II: tíbia p0; III: tíbia v0-1r-0, metatarso v2-2-2, p1-1-1, r1-1-1; IV: tíbia v1 r-1r-2. Palpo: apófise tibial retrolateral grossa, com concavidade pouco acentuada (Figs 18-19); projeção tegular afilada no ápice e disposta atrás do condutor de Anyphaeninae; êmbolo longo e sinuoso, com ápice encoberto pelo condutor de Anyphaeninae (Fig. 19)

Fêmea (parátipo). Coloração como no macho. 

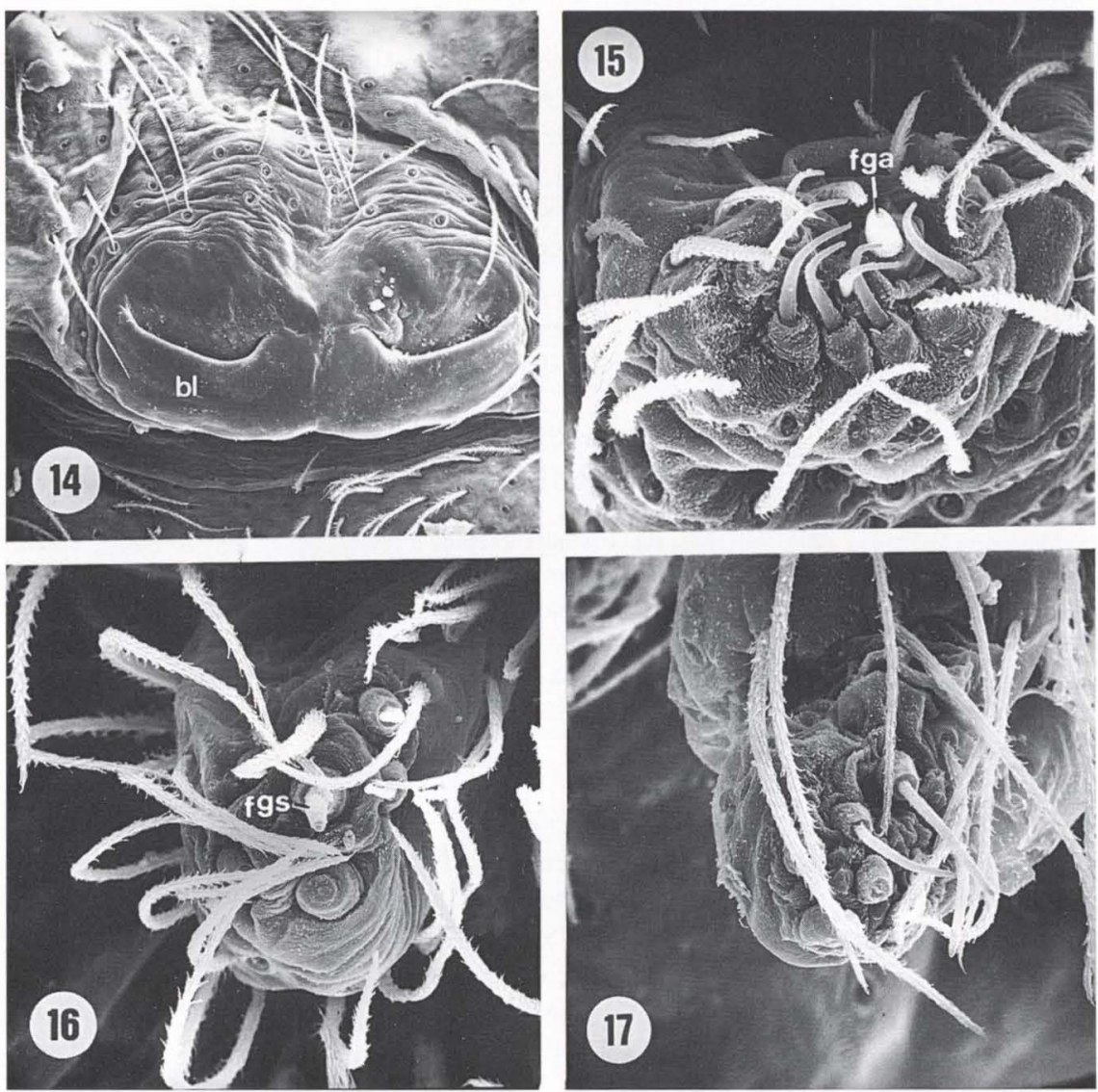

Figs 14-17. Lupettiana mordax, fêmea. (14) Epígino, ventral; (15-17) fiandeiras: (15) anterior, (16) média, (17) posterior. (bl) Borda lateral, (fga) fúsula da glândula ampular, (fgs) fúsula da glândula ampular secundária.

Comprimento total 2,70. Carapaça: comprimento 1,20, largura 0,85. Clípeo: altura 0,05 . Olhos: fila anterior 0,37 e posterior 0,50 . QOM: comprimento 0,17 , largura anterior 0,15, largura posterior 0,22. Diâmetros: OMA 0,06, OLA 0,08, OMP 0,08, OLP 0,08. Interdistâncias: OMA-OMA 0,04, OMA-OLA 0,05, OMPOMP 0,07, OMP-OLP 0,07, OLA-OLP 0,05. Quelíceras: 0,50 de comprimento, com 3 dentes na promargem e 3 dentículos na retromargem.

Abdômen. Comprimento 1,60, largura 0,90. Espiráculo traqueal distando 0,45 do sulco epigástrico e 0,55 da base das fiandeiras.

Pernas I: fêmur $0,90 /$ patela $0,40 /$ tíbia $0,75 /$ metatarso $0,65 /$ tarso $0,40 /$ total 3,10/ II: $0,80 / 0,35 / 0,60 / 0,55 / 0,30 / 2,60 /$ III: $0,60 / 0,30 / 0,45 / 0,50 / 0,20 / 2,05 /$ IV: $1,00 / 0,40 / 0,75 / 1,00 / 0,30 / 3,45$. Espinulação: pernas I: tíbia v2-2-2-2-1r; II: tíbia v2-2-2-2-1r; III: tíbia v0-1r-0, p0-1-0, r0-1-0, metatarso v2-0-2, p1-1-0; IV: tíbia v1r-1r-2, metatarso v1 r-1r-2. 

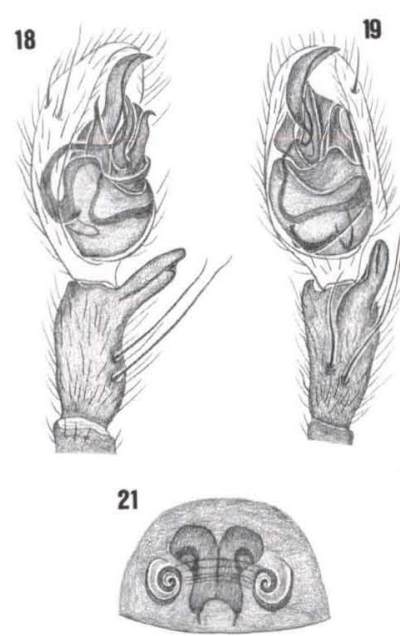

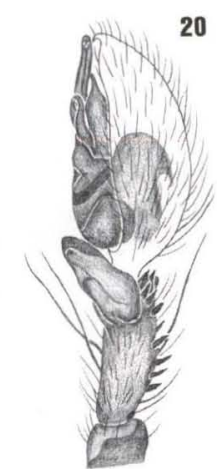

22

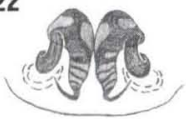

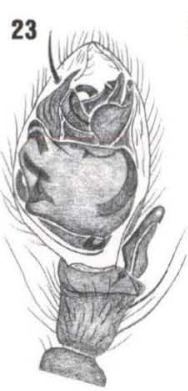

24
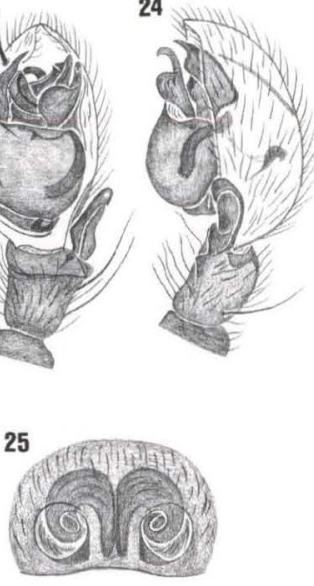

Figs 18-25. (18-22) Lupettiana parvula, macho, palpo: (18) ventral, (19) retrolateral, (20) prolateral; fêmea, epigino: (21) ventral, (22) dorsal; (23-24) L. eberhardi sp.n., macho, palpo: (23) ventral, (24) retrolateral, (25) L. spinosa, fêmea, epígino, ventral. Escalas: 0,25 mm.

Epígino: espermatecas alongadas, com maior espessura junto aos ductos de copulação, que são curtos, largos e curvados. Ductos de fertilização estreitos e alongados na base das espermatecas (Fig. 22).

Distribuição geográfica. Cuba, Haiti e República Dominicana.

Material examinado. RePÚBlica DominiCANa, Província Santiago Rodriguez: 7-12 km oeste de Monción, 1 fêmea, 5.X.1986 (BPBM); Monción, 1 fêmea, 22.X.1986, R. Greefield leg. (BPBM).

\section{Lupettiana eberhardi sp.n.}

\section{Figs 23-24}

Tipo. Holótipo macho, MCZ, Finca La Selva (50m alt.), próximo de Puerto Viejo, Heredia, Costa Rica, I.1978, W. Eberhard leg..

Etimologia. O nome específico é um patronímico ao coletor.

Diagnose. Machos de Lupettiana eberhardi diferem dos das demais espécies por apresentar uma projeção cônica na apófise tibial retrolateral (Fig. 24); apófise média com grande alargamento semicircular mediano e condutor de Anyphaeninae curto e subtriangular (Fig. 23).

Descrição. Macho (holótipo). Coloração como em L. mordax, exceto área distal dos metatarsos I, com uma banda cinza-escura.

Comprimento total 2,60. Carapaça: comprimento 1,10, largura 0,90. Clípeo: altura 0,04. Olhos: fila anterior 0,35 e posterior 0,46. QOM: comprimento 0,17, largura anterior 0,13, largura posterior 0,25. Diâmetros: OMA 0,05, OLA 0,10, OMP 0,08, OLP 0,08. Interdistâncias: OMA-OMA 0,02, OMA-OLA 0,02, OMPOMP 0,05, OMP-OLP 0,05, OLA-OLP 0,04. Quelíceras: 0,52 de comprimento, com quatro dentes na promargem e cinco dentículos na retromargem. 
Abdômen. Comprimento 1,40, largura 0,70. Espiráculo traqueal distando 0,45 do sulco epigástrico e 0,55 da base das fiandeiras. Pernas I: fêmur $0,80 /$ patela $0,35 /$ tíbia $0,80 /$ metatarso $0,65 /$ tarso $0,40 /$ total $3,00 /$ II: $0,75 / 0,35 / 0,75 / 0,55 /$ 0,35/ 2,75/ III: 0,60/ 0,30/0,45/0,55/0,25/2,15/ IV: 0,90/0,40/0,75/0,90/0,40/ 3,35. Espinulação: pernas I - II tíbia v2-2-2-2; III tíbia v0-1 p-0, p0-1-0, r0, metatarso v2-0-2, p1-0-1, r1-0-1; IV tíbia v0-1 p-0, p0-1-0, metatarso v1 p-0-2, p0-1-1. Palpo: tégulo sub-quadrangular na porção ventral e levemente sulcado prolateralmente; projeção tegular ventral afilada no ápice (Fig. 23).

Fêmea. Desconhecida.

Distribuição geográfica. Costa Rica.

Material examinado. Apenas o holótipo.

\section{Lupettiana spinosa (Bryant, 1948)}

Fig. 25

Temnida spinosa Bryant, 1948: 432, fig. 121 (holótipo fêmea, MCZ B054, Cordilheira Central, Loma Rucilla, República Dominicana (5000-8000m alt.), VII.1938, Darlington leg., examinado); Roewer, 1954: 546.

Lupettiana spinosa; Brescovit, 1996: 67.

Diagnose. A fêmea de Lupettiana spinosa assemelha-se à de L. parvula, mas difere desta pelos alargamentos externos das bordas laterais, que formam uma área subtriangular no epígino (Fig. 25).

Descrição. Macho desconhecido.

Fêmea (holótipo). Coloração como a de $L$. parvula, exceto pernas I e II marrom-escuras.

Comprimento total 3,50. Carapaça: comprimento 1,30, largura 1,00. Clípeo: altura 0,03 . Olhos: fila anterior 0,40 e posterior 0,57 . QOM: comprimento 0,22 , largura anterior 0,15 , largura posterior 0,27 . Diâmetros: OMA 0,05, OLA 0,10, OMP 0,08, OLP 0,08. Interdistâncias: OMA-OMA 0,05, OMA-OLA 0,04, OMPOMP 0,08, OMP-OLP 0,08, OLA-OLP 0,05. Quelíceras: 0,57 de comprimento, com três dentes na promargem e quatro dentículos na retromargem.

Abdômen. Comprimento 2,20, largura 1,30. Espiráculo traqueal distando 0,70 do sulco epigástrico e 0,85 da base das fiandeiras. Pernas I: fêmur $0,80 /$ patela $0,40 /$ tíbia $0,80 /$ metatarso $0,65 /$ tarso $0,35 /$ total $3,00 /$ II: $0,75 / 0,35 / 0,70 / 0,60 /$ 0,30/ 2,70/ III: 0,60/ 0,25/ 0,40/ 0,50/0,25/2,00/ IV: 0,90/0,40/0,70/0,80/0,30/ 3,10 . Espinulação: pernas III tíbia v0-1-2, p0, r0-1r-0, metatarso v1r-0-2, p0-0-1, r1-0-1; IV v1r-1r-2, p0, r0-1-0, metatarso v1p-0-2, p0-1-1. Epígino: espermatecas grandes, visualizadas por transparência (Fig. 25).

Distribuição geográfica. República Dominicana.

Material examinado. Apenas o holótipo.

\section{Lupettiana manauara sp.n.}

Figs 26-27

Tipo. Holótipo macho, INPA, Cidade Universitária, Manaus, Amazonas, Brasil, III.1979, J.A. Rafael leg.

Etimologia. O nome específico refere-se ao natural da cidade de Manaus. 
Diagnose. Machos de L. manauara diferem dos das demais espécies pelo grosso e sinuoso êmbolo e pelo acentuado sulco prolateral do tégulo, mostrando a curvatura basal do êmbolo (Fig. 26).

Descrição. Macho (holótipo). Coloração como em L. mordax.

Comprimento total 2,50. Carapaça: comprimento 1,10, largura 0,85. Clípeo: altura 0,04 . Olhos: fila anterior 0,37 e posterior 0,46 . QOM: comprimento 0,18 , largura anterior 0,18, largura posterior 0,27. Diâmetros: OMA 0,06, OLA 0,08, OMP 0,07, OLP 0,08. Interdistâncias: OMA-OMA 0,03, OMA-OLA 0,04, OMPOMP 0,08, OMP-OLP 0,06, OLA-OLP 0,03. Quelíceras: 0,60 de comprimento, com três dentes na promargem e cinco dentículos na retromargem.

Abdômen. Comprimento 1,40, largura 0,70. Espiráculo traqueal distando 0,50 do sulco epigástrico e 0,52 da base das fiandeiras. Pernas I: fêmur $0,70 /$ patela $0,40 /$ tíbia $0,65 /$ metatarso $0,55 /$ tarso $0,35 /$ total 2,65/ II: $0,65 / 0,25 / 0,60 / 0,45 /$ $0,30 / 2,25 /$ III: $0,55 / 0,30 / 0,35 / 0,55 / 0,25 / 2,00 /$ IV: $0,60 / 0,25 / 0,50 / 0,75 / 0,25 /$ 2,35. Espinulação: pernas I metatarso v2-2-0, II tíbia v1r-2-0, matatarso v2-2-0; III tíbia r1-1-0, metatarso pl-1-0, r1-1-0; IV tíbia v0-1p-0, p0, r0, metatarso v0-0-2, p0-0-1, r0-0-1. Palpo: apófise tibial retrolateral similar a de L. mordax, mas com uma aba basal esclerotinizada (Fig. 27); apófise média e condutor de Anyphaeninae muito curtos; projeção tegular ventral estreita e alongada (Fig. 26).

Fêmea. Desconhecida.

Distribuição geográfica. Amazonas, Brasil.

Material examinado. Sómente o holótipo.

\section{Lupettiana piedra sp.n.}

Figs $28-29$

Tipo. Holótipo macho, AMNH, Sierra de La Torre, Gran Piedra, Oriente, Cuba, 29.VI.1955, A. Archer leg. .

Etimologia. O nome específico é um substantivo referente à localidade-tipo.

Diagnose. O macho de Lupettiana piedra difere dos das demais espécies por apresentar projeções cônicas basais ventrais e dorsais na apófise tibial retrolateral (Fig. 29) e projeção tibial retrolateral ventral volumosa, longa e de ápice truncado (Fig. 28).

Descrição. Macho (holótipo). Coloração como em L. mordax.

Comprimento total 3,50. Carapaça: comprimento 1,60, largura 1,25. Clípeo: altura 0,06 . Olhos: fila anterior 0,52 e posterior 0,63 . QOM: comprimento 0,26 , largura anterior 0,22, largura posterior 0,32. Diâmetros: OMA 0,10, OLA 0,12, OMP 0,10, OLP 0,10. Interdistâncias: OMA-OMA 0,05, OMA-OLA 0,05, OMPOMP 0,08, OMP-OLP 0,10, OLA-OLP 0,05. Quelíceras: 0,85 de comprimento, com cinco dentes na promargem e cinco dentículos na retromargem.

Abdômen. Comprimento 2,00, largura 1,10. Espiráculo traqueal distando 0,40 do sulco epigástrico e 0,65 da base das fiandeiras. Pernas I: fêmur $1,30 /$ patela $0,60 /$ tíbia $1,30 /$ metatarso $1,10 /$ tarso $0,55 /$ total $4,85 /$ II: $1,15 / 0,50 / 1,15 / 0,90 /$ 0,45/ 4,15/ III: $0,90 / 0,35 / 0,60 / 0,85 / 0,30 / 3,00 /$ IV: $1,30 / 0,50 / 1,10 / 1,40 / 0,40 /$ 
4,70. Espinulação: pernas I - II tíbia v2-2-2-2-2; III tíbia v1p-1r-0, p0-1-0, r0-1-0, metatarso v2-0-2, p1-0-1, r1-0-1; IV tíbia v1p-1p-1r, metatarso v2-1p-2. Palpo: tégulo fortemente sulcado medianamente; condutor de Anyphaeninae de base engrossada, com dois braços distais, um curto e cônico anterior e um alongado, de ápice curvado posterior, e entre os quais repousa a região distal do êmbolo (Fig. 28).

Fêmea. Desconhecida.

Distribuição geográfica. Cuba.

Material examinado. Apenas o holótipo.
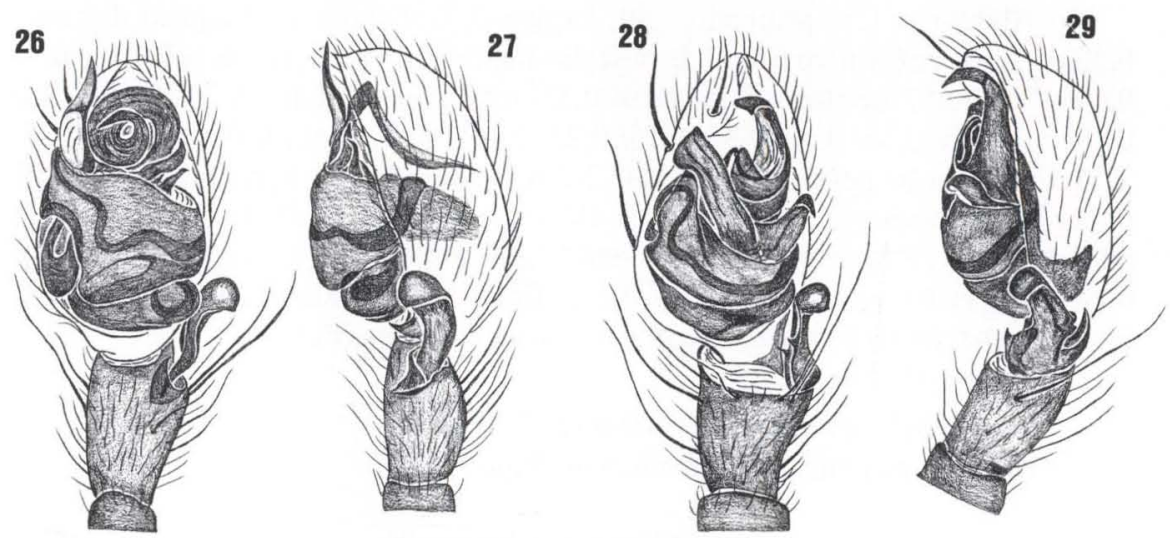

Figs 26-29. (26-27) Lupettiana manauara sp.n., macho, palpo: (26) ventral, (27) retrolateral, (28-29) L. piedra sp.n., macho, palpo: (28) ventral; (29) retrolateral. Escalas: 0,25 mm.

\section{Lupettiana levii sp.n.}

Figs $30-32$

Tipo. Holótipo macho, MCZ, Jardim Botânico, Santo Domingo, Santo Domingo, República Dominicana, 18-22.III.1984, H. \& L. Levi leg. .

Etimologia. O nome específico é um patronímico a um dos coletores do holótipo, o aracnólogo Herbert W. Levi.

Diagnose. Machos de Lupettiana levii assemelham-se ao de L. linguanea por apresentar condutor de Anyphaeninae falciforme, mas difere desta por este ser mais estreito e mais longo e a apófise média mais longa e fortemente curvada na base (Figs 30-31); e, apófise tibial retrolateral curvada na região mediana (Fig. 31).

Descrição. Macho (holótipo). Carapaça laranja, com região cefálica e bordas laterais marrom-esverdeadas. Quelíceras, lábio, lâminas maxilares marrom-avermelhadas. Esterno cinza esverdeado. Abdômen marrom-avermelhado, com bandas transversais medianas dorsais negras (Fig. 32). Fiandeiras marrom-avermelhadas. Pernas alaranjadas, com ápices das coxas, tíbias e metatarsos marrons. 
Comprimento total 3,80. Carapaça: comprimento 1,55, largura 1,20. Clípeo: altura 0,05 . Olhos: fila anterior 0,45 e posterior 0,57 . QOM: comprimento 0,22 , largura anterior 0,20, largura posterior 0,27. Diâmetros: OMA 0,07, OLA 0,10, OMP 0,10, OLP 0,09. Interdistâncias: OMA-OMA 0,05, OMA-OLA 0,05, OMPOMP 0,10, OMP-OLP 0,10, OLA-OLP 0,05. Quelíceras: 0,85 de comprimento, com cinco dentes na promargem, o quarto a partir da garra muito grande, e cinco dentículos na retromargem.

Abdômen. Comprimento 2,20, largura 0,90. Espiráculo traqueal distando 0,60 do sulco epigástrico e 0,85 da base das fiandeiras. Pernas I: ausente/ II: fêmur $1,30 /$ patela $0,55 /$ tíbia $1,20 /$ metatarso $1,05 /$ tarso $0,50 /$ total 4,60/ III: $0,90 / 0,50 /$ $0,70 / 0,90 / 0,40 / 3,40 /$ IV: $1,40 / 0,60 / 1,20 / 1,50 / 0,45 / 5,15$. Espinulação: pernas II tíbia v1 r-2-1r, p1-1-0, metatarso v2-2-0; III tíbia v2-1 p-2, r1-1-0, metatarso v2-2-2, p1-1-1, rl-1-1; IV tíbia v2-2-2, metatarso v2-2-2. Palpo: tíbia curta, com acentuada escavação na base da apófise tibial retrolateral (Fig. 31); êmbolo muito longo e filiforme (Fig. 30).

Fêmea. Desconhecida.

Distribuição geográfica. República Dominicana.

Material examinado. Somente o holótipo.

\section{Lupettiana bimini sp.n.}

Figs 33-36

Tipos. Holótipo macho, alótipo fêmea, AMNH, South Bimini, Ilha Bimini, Ilhas Bahamas, V.1951, W.J. Gertsch, M.A. Cazier leg. Parátipos: 1 macho 1 fềmea, IBSP, com os mesmos dados do holótipo.

Etimologia. O nome específico é um substantivo referente à localidade-tipo.

Diagnose. Os machos de Lupettiana bimini são separados dos machos das demais espécies por apresentarem projeção basal da apófise tibial retrolateral subtriangular (Fig. 34) e projeção tegular ventral muito alargada distalmente e uma pequena projeção digitiforme látero-distal no tégulo (Fig. 33). A fềmea difere das demais por apresentar um borda anterior semicircular e as bordas laterais alongadas e muito sinuosas (Fig. 35).

Descrição. Macho (holótipo). Coloração como em L. mordax.

Comprimento total 3,30. Carapaça: comprimento 1,60, largura 1,20. Clípeo: altura 0,05 . Olhos: fila anterior 0,56 e posterior 0,70 . QOM: comprimento 0,20 , largura anterior 0,21 , largura posterior 0,35. Diâmetros: OMA 0,10, OLA 0,12, OMP 0,12, OLP 0,12. Interdistâncias: OMA-OMA 0,05, OMA-OLA 0,04, OMPOMP 0,10, OMP-OLP 0,08, OLA-OLP 0,05. Quelíceras: 1,10 de comprimento, com quatro dentes na promargem e quatro dentículos na retromargem.

Abdômen. Comprimento 1,80, largura 0,90. Espiráculo traqueal distando 0,30 do sulco epigástrico e 0,70 da base das fiandeiras. Pernas I: fêmur $1,30 /$ patela $0,60 /$ tíbia $1,20 /$ metatarso $1,10 /$ tarso $0,50 /$ total $4,70 /$ II: $1,15 / 0,55 / 1,05 / 0,90 /$ 0,40/ 4,05/ III: $0,85 / 0,40 / 0,50 / 0,75 / 0,30 / 2,80 /$ IV: $1,30 / 0,50 / 1,00 / 1,40 / 0,40 /$ 4,60. Espinulação: pernas II tíbia v2-2-2-2-2, p0; III tíbia v1 p-1 p-0, p0-1-0, r0-1-0, 

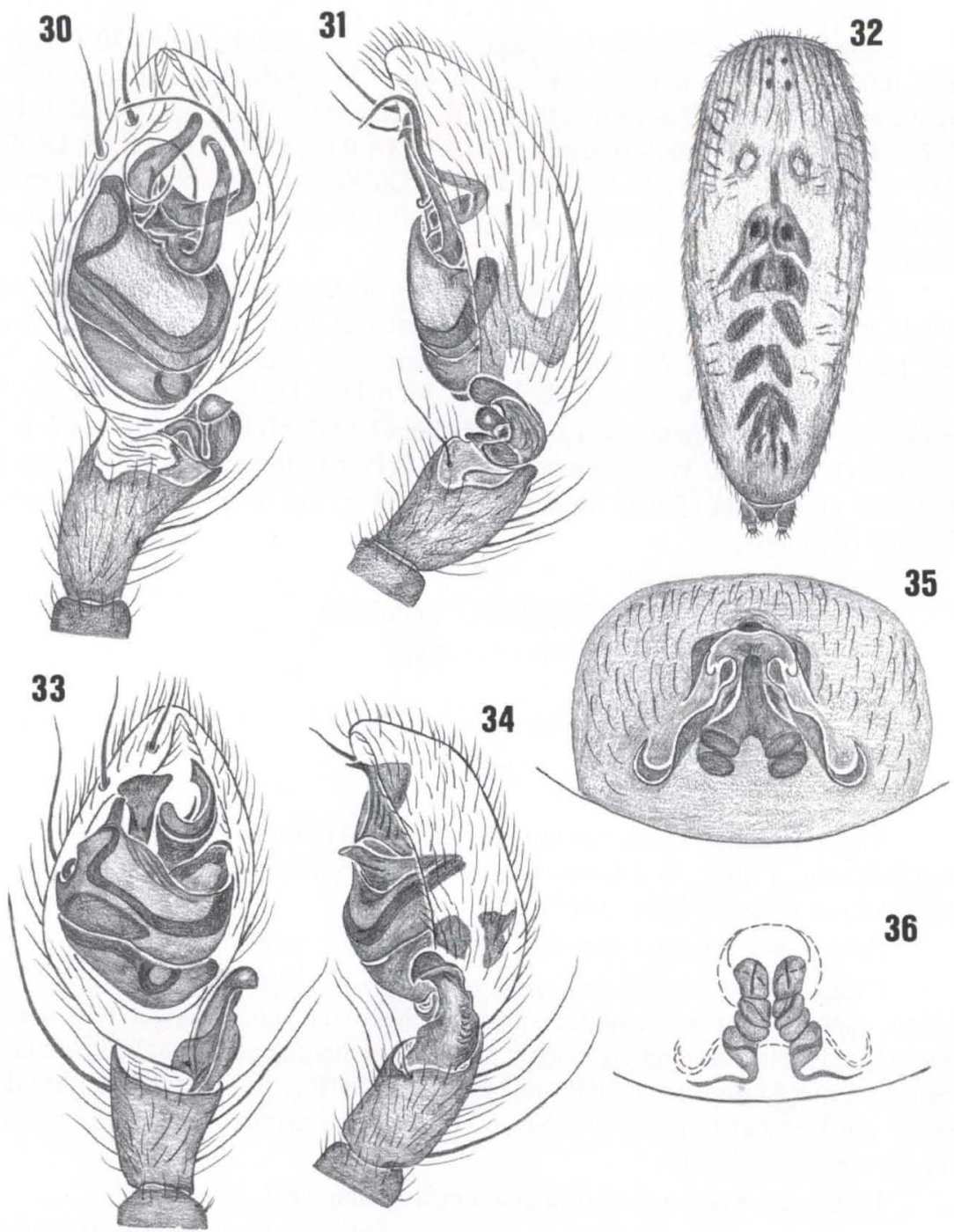

Figs 30-36. (31-32) Lupettiana levii sp.n., macho, palpo: (30) ventral, (31) retrolateral; abdômen: (32) dorsal; (33-36) L. bimini sp.n., macho, palpo: (33) ventral, (34) retrolateral; fêmea, epigino: (35) ventral, (36) dorsal. Escalas: 0,25 mm.

metatarso v2-0-2, p1-0-1, r1-0-1; IV tíbia v1p-1p-2, metatarso v2-0-2. Palpo: apófise tibial retrolateral com sinuosidades dorsais (Fig. 34); apófise média curta e larga; êmbolo curto (Fig. 33).

Fêmea (alótipo AMNH). Coloração como a do macho.

Comprimento total 4,20. Carapaça: comprimento 1,60, largura 1,10. Clípeo: altura 0,05. Olhos: fila anterior 0,52 e posterior 0,65. QOM: comprimento 0,20, 
largura anterior 0,21, largura posterior 0,35. Diâmetros: OMA 0,10, OLA 0,12, OMP 0,10, OLP 0,11. Interdistâncias: OMA-OMA 0,04, OMA-OLA 0,04, OMPOMP 0,10, OMP-OLP 0,10, OLA-OLP 0,05. Quelíceras: 0,77 de comprimento, com quatro dentes na promargem e cinco dentículos na retromargem.

Abdômen. Comprimento 2,70, largura 1,40. Espiráculo traqueal distando 0,60 do sulco epigástrico e 0,80 da base das fiandeiras.

Pernas I: fềmur $1,20 /$ patela $0,65 /$ tíbia $1,15 /$ metatarso $0,85 /$ tarso $0,45 /$ total 4,30/ II: $1,00 / 0,50 / 0,85 / 0,80 / 0,40 / 3,55 /$ III: $0,75 / 0,40 / 0,50 / 0,70 / 0,30 / 2,65 /$ IV: $1,10 / 0,55 / 1,00 / 1,30 / 0,40 / 4,35$. Espinulação: pernas II tíbia v2-2-2-2-2, p0; III tíbia v1p-1p-2, r0, metatarso v2-1r-2, p1-0-1, r1-0-1; IV tíbia v1p-1p-1r, metatarso v2-0-2. Epígino: átrio subovalado e pouco profundo (Fig. 35); espermatecas longas, estreitas, com muitas sinuosidades; ductos de copulação inconspícuos; e, ductos de fertilização basais, longos e estreitos (Fig. 36).

Variação. Comprimento (4 machos): total 3,10-3,50; Carapaça 1,40-1,60; fêmur I 1,00-1,30; (5 fêmeas): total 3,30-4,20; Carapaça 1,30-1,60; fêmur I 1,001,20 .

Distribuição geográfica. Ilhas Bahamas.

Material examinado. IlHAS BAHAMAs, Ilha Bimini: South Bimini, 2 fêmeas, V.1951, W.J. Gertsch, M.A. Cazier leg. (AMNH); 1 macho, VI.1951, M.A. Cazier, C. \& P. Vaurierleg. (AMNH); 1 fêmea, 12-18.XII.1952, A.M. Nadlerleg. (AMNH); 1 macho, 22-28.III.1953, A.M. Nadler leg. (AMNH).

AGRADECIMENTOS. Aos curadores, acima listados, pelo empréstimo do material. Ao operador V. Zibat (UK) pela ajuda na elaboração das fotos no microscópio eletrônico de varredura. À Martín J. Ramírez pelas críticas ao manuscrito. Ao Conselho Nacional de Desenvolvimento Científico e Tecnológico (CNPq) e à Fapesp, processo $n^{\circ}$ 96/7052-9 pelos auxílios concedidos.

\section{REFERÊNCIAS BIBLIOGRÁFICAS}

BANKS, N. 1903. A list of Arachnida from Hayti, with descriptions of new species. Proc. Acad. nat. Sci. Philad. 55: 340-345.

- 1909. Aracnidos de Cuba. Est. Central Agron., Second Report, Habana, 2: $150-174$.

Bonnet, P. 1959. Bibliographia Araneorum. Toulouse, Ed. Douladoure, Vol. 2, p. $4231-5058$.

Brescovit, A.D. 1996. Revisão de Anyphaeninae Bertkau a nível de gêneros na região neotropical (Araneae, Anyphaenidae). Revta bras. Zool. 13 (Supl. 1): 1-187.

BRyant, E.B. 1940. Cuban spiders in the Museum of Comparative Zoology. Bull.

Mus. comp. Zool. 86: 247-554.

- 1948. The spiders of Hispaniola. Bull. Mus. comp. Zool. 100: 331-447.

LEVI, H.W. 1965. Techniques for the study of spider genitalia. Psyche 72: 152-158. P.-CAMBridge, O. 1896. Arachnida-Araneida, p.161-224. In: F.D. GodMAN \& O. SALvin (Eds). Biologia Centrali-Americana. London, Vol. 1, 317p. 
PLATNICK, N.I. 1974. The spider family Anyphaenidae in America North of Mexico.

Bull. Mus. comp. Zool. 146: 205-266.

RAMíREZ, M.J. 1995. A phylogenetic analysis of the subfamilies of Anyphaenidae (Arachnida, Araneae). Ent. scand. 26: 361-384.

RoEWER, C.F. 1954. Katalog der Araneae von 1758 bis 1940. Bruxelles, Vol. 2, p. 1-923.

Recebido em 12.XI.1998; aceito em 16.XI.1999. 